\title{
$\begin{array}{lllllllll}\mathrm{I} & \mathrm{N} & \mathrm{S} & \mathrm{T} & \mathrm{I} & \mathrm{T} & \mathrm{U} & \mathrm{T} & \mathrm{E}\end{array}$
}

\section{Reading Levels of Rural and Urban Third Graders Lag Behind Their Suburban Peers}

SUZANNE E. GRAHAM AND CHRISTINE TEAGUE

$\mathrm{T}$

Third grade reading achievement is critical to later academic and occupational success. Students who are strong readers early in school do well in other subjects and are subsequently more likely to graduate from high school and attend college. ${ }^{1}$ Many factors affect early literacy, including aspects of the child's home environment, school experiences, and community wealth. Because of potential differences in such characteristics for children as a function of the type of place a child lives, we consider whether living in a rural, urban, or suburban area is related to reading achievement and, if so, how. We also consider the impact of both a family's socioeconomic status and the child's reading achievement level at the beginning of kindergarten. We end with potential reasons for the differences between rural, urban, and suburban schools.

\section{Average Third Grade Reading Achievement Is Lower for Rural and Urban Children}

The reading score of an average third grade rural student in the United States is 122 points on a scale ranging from 0 to 212 . This score is nearly eight points, or roughly one-third of a standard deviation, ${ }^{2}$ lower than the score of an average suburban student (see Table 1). The average urban student's score (124) is similar to rural students and six points lower than the suburban student average. Although these differences are not large, even small differences in third grade reading achievement can have important effects on later educational outcomes. ${ }^{3}$

\section{Key Findings}

- Rural and urban third graders have lower average reading achievement levels than their suburban peers.

- Suburban children realize greater gains in reading achievement from kindergarten to Grade 3 than their rural or urban counterparts.

- Third grade reading achievement gaps between rural, urban, and suburban children are associated with socioeconomic background differences.

- Rural students who were struggling readers at the beginning of kindergarten have lower average reading achievement in third grade than both urban and suburban students when children of the same socioeconomic status are compared.

- There are no average achievement differences by location for third graders who were high achievers at the start of kindergarten.

- Only 27 percent of teachers in rural schools report active professional development programs in their schools, compared with 40 percent of teachers in suburban and urban schools. 
Table 1. Average Reading Achievement in Kindergarten (FAll) and Third Grade (Spring) ${ }^{a}$

\begin{tabular}{lccc}
\hline Location & Kindergarten & Grade 3 & Achievement Gain \\
\hline Rural & 33 & 122 & 89 \\
Urban & 34 & 124 & 90 \\
Suburban & 36 & 130 & 94 \\
$\begin{array}{l}\text { Rural-suburban } \\
\text { difference' }\end{array}$ & -3 & -8 & -5 \\
$\begin{array}{l}\text { Urban-suburban } \\
\text { difference' }\end{array}$ & -2 & -6 & -4 \\
\hline
\end{tabular}

a. The sample size is 8,405 . The analysis was conducted using weights appropriate for the complex survey sampling design of the Early Childhood Longitudinal Study. b. All differences are statistically significant at the .001 level.

\section{Suburban Kindergarteners Enter School Reading at Slightly Higher Levels than Urban and Rural Youth and See Larger Gains over Time}

To some extent, the differences in average reading achievement for rural, urban, and suburban third graders reflect average achievement differences at the start of kindergarten. As shown in the first column of Table 1, the average reading achievement levels for rural and urban students are similar (33 versus 34 points). Suburban kindergarteners, however, score on average two to three points above their urban and rural peers. Although the differences in kindergarten reading achievement are statistically significant, they are not large. ${ }^{4}$

In addition, the average reading gains from kindergarten through Grade 3 for rural and urban children are lower than the gains for suburban children (Figure 1). ${ }^{5}$ Although the learning curves are steep for all three groups, the trajectory in reading is steeper for suburban than urban and rural children.

Figure 1. Average Estimated Reading Advances between Kindergarten (FAll) ANd Grade 3 (Spring)

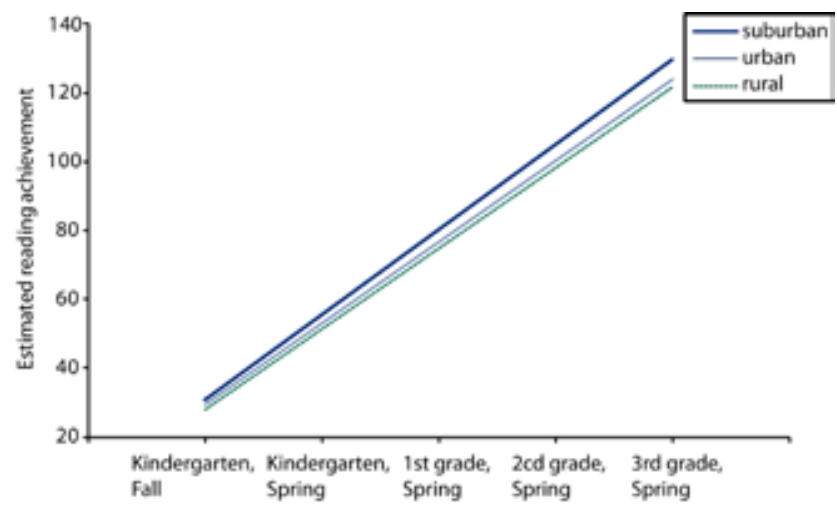

Family Socioeconomic Background Underlies Rural, Urban, and Suburban Differences in Reading

As past research has documented, family socioeconomic status plays a large role in reading achievement. ${ }^{6}$ Students in families with higher socioeconomic status start school with higher achievement levels than their peers from less advantaged backgrounds. Because families living in rural and urban communities, on average, are poorer than their suburban counterparts, it is important to take these differences into account when comparing reading achievement. Indeed, we find no differences in third grade reading achievement between rural, urban, and suburban students when we compare students from similar socioeconomic backgrounds. Therefore, the average achievement differences described above say more about average socioeconomic differences in families from rural, urban, and suburban areas than about the impact of location.

\section{Rural Students Who Begin Kindergarten Struggling to Read Have Lower Third Grade Reading Achievement than Their Suburban and Urban Counterparts}

Although we find no average differences in third grade reading achievement for rural, urban, and suburban children from similar socioeconomic backgrounds, when we also consider the impact of prior reading achievement we again find differences in average achievement as a function of location, but only for students who had lower levels of reading achievement in kindergarten. Specifically, comparing students of similar socioeconomic backgrounds, rural students who were low achievers at the beginning of kindergarten have fallen behind their suburban and urban counterparts by third grade. For example, we estimate that the average reading achievement of a rural third grader who scores in the tenth percentile of reading achievement in kindergarten is approximately 6 to 7 points lower than the reading achievement of the average suburban and urban third grader with comparable kindergarten achievement and socioeconomic background. In contrast, rural, urban, and suburban students who start kindergarten with high levels of reading achievement do not score differently from each other in third grade, on average. 


\section{Potential Explanations for These Differences}

Reading achievement represents a complex interplay of family, school, and community factors. We offer a few potential reasons for the differences in third grade reading achievement by location for children who begin public school already behind.

First, the differences in reading achievement at the start of kindergarten may reflect differences in preschool attendance among rural students. Other studies have found that rural children are less likely to attend preschool than urban and suburban children. ${ }^{7}$ In 2005,50 percent of rural 3- to 5-yearolds were in center-based preschool programs compared with 57 percent nationally. ${ }^{8}$

In addition, parents of rural children tend to have less education than urban and suburban parents. In 2004, 33 percent of mothers and 36 percent of fathers of school-aged children in rural areas had only a high school degree. This compares with 25 percent of mothers and 24 percent of fathers in the suburbs, and 26 percent of mothers and 23 percent of fathers in urban areas. ${ }^{9}$

The differences in third grade reading achievement between rural and nonrural children who were low achievers in kindergarten most likely reflect different educational opportunities and school resources available to these children. Using data from the schools participating in the Early Childhood Education Study, we find that only 39 percent of the teachers in rural schools believed that their school library was always adequate. This compares with 46 percent in suburban schools and 61 percent in urban schools. Likewise, nearly 13 percent of rural teachers indicated that their classrooms were never adequate or often inadequate for teaching compared with 11 percent of teachers in suburban and 9 percent of teachers in urban schools. These differences are consistent with other reports of teachers' perceptions of school facilities. ${ }^{10}$

Professional development for teachers is also an important resource. ${ }^{11}$ Exactly how these factors interact with student literacy is not fully understood, but it is clear that many types of professional development programs (including web-based coaching) represent promising approaches to strengthening early literacy, particularly for low-income struggling readers. ${ }^{12}$ Yet, rural teachers are less likely to report excellent or good professional development opportunities in their schools. ${ }^{13}$ In the current study, only 27 percent of the teachers in rural schools indicated that there were active professional development programs in their schools. This compares with 40 percent of teachers in suburban and urban schools. Improved professional development opportunities for rural teachers may help narrow the differences in the third grade reading achievement of rural, urban, and suburban students who were struggling readers in kindergarten.
Data

The data in this brief are from the Early Childhood Longitudinal Study, a multiyear study of a nationally representative sample of more than 22,000 children between 1998 and 2006. Children were surveyed two times during kindergarten, then in the spring of Grades 1, 3, 5, and 8. Teachers, parents, and school administrators were also surveyed. The analytic sample used for the brief consists of the 8,405 public school students for whom information was available on K-3 reading achievement, school location, ${ }^{14}$ family socioeconomic status, child race or ethnicity, and gender. Descriptive information on schools comes from the 443 public schools with information available about school resources and professional development programs. Differences discussed in the text are all statistically significant $(\mathrm{p}<0.05)$.

\section{EN D N O TES}

1. See, for example, Preventing Reading Difficulties in Young Children, edited by C. E. Snow, S. Burns and P. Griffin, Washington, DC: National Academy Press, 1998.

2. A standard deviation is a common measure of variability in a set of data. It can be interpreted generally as an average deviation of the values from an overall mean, although its technical calculation is more complex (see any introductory statistics book for the exact formula).

3. Snow, Burns, and Griffin, Preventing Reading Difficulties in Young Children.

4. The differences represent approximately $20-30$ percent of the kindergarten reading achievement standard deviation of nearly 10 points.

5 . We obtained fitted change trajectories by fitting multilevel models for change using third grade reading achievement as the outcome, and fall of kindergarten as the start point. For a description of the multilevel model for change, see $S$. E. Graham, J.D. Singer, and J. B. Willett, "An Introduction to the Multilevel Model for Change." In Handbook of Social Research Methods, edited by P. Alasuutari, L. Bickman, and J. Brannon (London: Sage, 2008).

6. G. Roberts, S. S. Mohammed, and S. Vaughn, "Reading Achievement Across Three Language Groups: Growth Estimates for Overall Reading and Reading Subskills Obtained with the Early Childhood Longitudinal Survey," Journal of Educational Psychology, vol. 102 (2010): 668-686.

7. National Center for Rural Early Childhood Learning Initiatives, "Preliminary Rural Analysis of the Early Childhood Longitudinal Study-Kindergarten Cohort." Rural Early Childhood brief 2. (Mississippi State: Mississippi State University, 2005). 
8. S. Provasnik et al., Status of Education in Rural America. NCES 2007-040. (Washington, DC: National Center for Education Statistics, Institute of Education Sciences, U.S. Department of Education, 2007).

9. Ibid.

10. D. Marlow and M. Cooper, The MetLife Survey of the American Teacher, Past, Present, and Future. (New York: MetLife, Inc., 2008).

11. For example, struggling kindergarten students experienced larger reading gains when their teachers participated in practice-based professional development programs. A. McGill-Franzen, R. L. Payne, and D. V. Dennis, "Responsive Intervention: What Is the Role of Appropriate Assessment?" In RTI in Literacy-Responsive and Comprehensive, edited by P. H. Johnston. (Newark, DE: International Reading Association, 2010). In addition, a study of early childhood education professional development programs serving low-income students finds statistically significant positive effects on student language and literacy development when professional development combined practice-based components with knowledge-focused components. See S. B. Neuman and Linda Cunningham, "The Impact of Professional Development and Coaching on Early Literacy Instructional Practice," American Educational Research Journal, vol. 46 (2009): 532-566.

12. B. Wasik and A. H. Hindman, "Identifying critical components of an effective preschool language and literacy coaching intervention." In Handbook of Early Literacy, vol. 3, edited by S. Neuman and D. K. Dickenson (New York: Guilford Press, 2011).

13. Marlow and Cooper, The MetLife Survey of the American Teacher.

14. The definition of rural used in the Early Childhood Longitudinal Study is based on definitions used by the U.S. Census Bureau. Rural communities are defined as locations with 2,500 or fewer residents, or small towns with 25,000 or fewer residents.

\section{A BOUT THE AUTHORS}

Suzanne E. Graham is an associate professor in the Department of Education at the University of New Hampshire.

(suzanne.graham@unh.edu)

Christine Teague is a doctoral student in the Department of Education at the University of New Hampshire.

(csteague@hotmail.com)

\section{A C K N O W L E D G M E N T S}

The authors thank Mil Duncan, Curt Grimm, Laurel Lloyd Earnshaw, Beth Mattingly, and Amy Sterndale at the Carsey Institute and Barbara Ray at Hired Pen for their thoughtful comments and suggestions.

\section{ANIVERSITY}

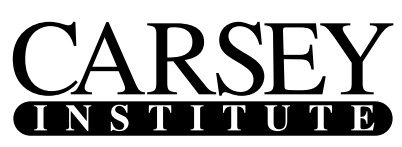

Building knowledge for families and communities

The Carsey Institute conducts policy research on vulnerable children, youth, and families and on sustainable community development. We give policy makers and practitioners timely, independent resources to effect change in their communities.

This work was supported by the Annie E. Casey Foundation, the W. K. Kellogg Foundation, and an anonymous donor.

Huddleston Hall

73 Main Street

Durham, NH 03824

$(603) 862-2821$

www.carseyinstitute.unh.edu 